ing mass are properly timed to brith about the increasing amplitudes.

The subject is treated analytically in the same journal by A. Hartwich, Vol. 17, 27, 1914. He arrives at an expression identical with that for Kepler's seeond law.

\section{PaUl E. Klopstiea}

Primabeititis; July $9 ; 1919$

\section{SCIENTIFIC BOOKS}

Sewage Dispösâl. By teoñàd P. Kinnioutic, late Director Department of Chemistry, and Professor of Sanitary Chemistry in the Worcester Polytechnic Institute; O.-E. A. WinsLow, Professor of Public Health in the Yale School of Medicine and Curator of Public Health in the American Museum of Natural History, New York; and R. WrNthrop Pratt, Consulting Engineer, M.Am. Soc.C.E. Second Edition, retrittên. New York, John Wiley \& Sons, Inc.; Lòndon, Chapman \& Hall, Ltd. Cloth; $6 \times 9$ in. Pp. 547. Illustrated. $\$ 4.00$.

The first edition of this book which was reviewed by the writer in ScIence, February 10, 1911, Volume XXXIII., page 222, has been a successful reference book for students studying the fundamental principles of this branch of municipal sanitation. The present edition has been thoroughly revised and increased in size by abdut one Hurdred paǵes.

Progress has been rapid during recent jears in this branch of the field of municipal sanitation. The revision of this book is timely as it is generally recognized that activities along this line, retarded by the world war, will shortly be taken up again with renewed vigor.

The style of the book is attractive and it is well arranged for use in the class room. Fundamental pritrciples are clearly stated and use is made liberally of practical illustrations drawn from rarious important documents and investigations not only in this country, but abroad.

In bringing the book up to date, attention has been paid in particular to the activated sludge process, the two-story tank for the remotal of suspended solids, with a comprehenisive redital of advantiges and disadvant taiges as how undèrstobd, and improvernetis in the fine sereenitig of setwage, atid protgress in dispơsal of stwage sludge and the recotier of gréase and fertilizing constituents froth these waste products. Investigations conducted on a coniprehensive scale at Cleté land, Ohicágo, Milwaukee and New Haven are described summaries of restults, as published. Orie of the therits of the bodk is that it is written from the viewpoints of the engis neer, the chemist and the bacteriologist, thus bringing out for the consideration of the sanitarian atid student the general principles of the subject from the angles stated, as is necessary in order to appreciate the practicability and efficieney of the resplective methodls.

The authors deserve contrimendation for their temperate staterients on topics where current literature shows differences of opinion due presumably to variations in local dothditions not as yet fully understood.

Iittle attempt has been made to set forth completely the trost recent results obtainied from the operation of plants most lately installed in this country. This may prove diss appointing to some tho derotie themselves entirely to work in this particular field, but it is probably wise on the part of the authors to base book for class room use on the broad historic background which is stated in the preface, forms the surest basis for real comprehension of the general principles of the subject as now understood. Teachers and students of this subject should welcome this new volume.

GEorgè W. Fúliter

\section{SPECIAI ARTICLES}

THE POSSTBLE PRESENCE OF CORONIUM IN HELIU FROM NATURAL GAS

ON of us (Cady), with McFarland, ${ }^{1}$ observed a number of lines in the spectra of samples of helium obtained from natural gas which did not belong in the spectra of helium,

2 Kansas Unitersity Geological Survey, "The Compobition of Natural Gas," p. 264.

a Proc. Roy. Soc.; 67, 467, 1901. 